\title{
Algoritmos do prazer: uso da tecnologia no âmbito da sexualidade; implicações da prática clínica
}

\author{
Algorithms of pleasure: use of technology in the context \\ of sexuality; implications of clinical practice
}

\section{Jamile Peixoto Pereira}

\begin{abstract}
Resumo: $O$ artigo visa anunciar meios de interação possibilitados por meio do uso de recursos tecnológicos e suas implicações no âmbito da sexualidade. Cada vez mais, a prática clínica desafia a pensar no tema e investir em mecanismos que não somente nos aproximem das experiências virtuais, mas nos auxiliem na compreensão da complexidade dos casos. Com propósito de buscar entendimento e uma medida saudável para usuários das interações virtuais, surgiu a proposta de uma espécie de algorítimo do prazer, conceito trazido pelas ciências da computação, adaptado às noções e vivências dos processos psicoterapêuticos. Os relatos da vivência cotidiana são lançados como uma forma de ampliar a discussão e proposição de estratégias clínicas que auxiliem no acolhimento e intervenções diante de demandas que propiciam repensar os investimentos acerca da sexualidade e tecnologia.
\end{abstract}

Palavras-chave: Algorítmo; Prazer, Sexualidade; Tecnologia; Psicoterapia.

\begin{abstract}
The article aims to announce the means of interaction enable through the use of technological resources and their implications in the ambit of sexuality. Increasingly, clinical practice challenges to think about the topic and invest in mechanisms that not only bring us closer to virtual experiences but help us understand the complexity of cases. With the purpose to seek understanding and a healthy measure for users of virtual interactions, the proposal for a kind of pleasure algorithm emerged, a concept brought by computer science, adapted to the notions and experiences of psychotherapeutic processes. The reports of everyday experience are launched as a way to expand the discussion and proposition of clinical strategies that assist in welcoming and interventions in the face of demands that allow rethinking investments about sexuality and technology.
\end{abstract}

Keywords: Algorithm; Pleasure, Sexuality; Technology; Psychotherapy. 
Mudanças socioculturais, no contexto atual de ampliação do acesso à internet, vêm produzindo outros modos de relacionamentos interpessoais no contexto social e íntimo. Na medida em que se tornam mais acessíveis no contexto global, as vivências on-line despertam certo grau de curiosidade e infinitas possibilidades, principalmente, nos modos de relação afetiva e sexual.

A utilização de redes sociais para fins afetivos e sexuais é muito comum. Pode estar relacionada às novas experiências entre casais ou, também, para pessoas solteiras que buscam outros modos de ampliar as conexões e experiências. No contexto clínico em psicoterapia, surgem cada vez mais relatos e vivências nesse âmbito, por isso discutir o assunto é um tema pertinente e necessário na atualidade.

Nesse sentido, é importante avaliarmos e construirmos, nos processos psicoterapêuticos, o que pode ser positivo para os objetivos do indivíduo, discernindo daquilo que provoca sofrimento ou pode gerar frustração. Cabe ficarmos atentos, com olhar cauteloso, para problemas relacionados à compulsão, isolamento social e implicações de demais patologias, levando os sujeitos ao reforço da individualidade como mecanismo de defesa e um modo de superar suas dificuldades.

Para transitar na complexidade e amplitude do tema, a proposta é entendermos o algoritmo do prazer como um modo de construção de um modelo que se repete ao propor um passo a passo, condicionado à determinada finalidade, como acontece na construção do algoritmo. 0 conceito de algoritmo, utilizado pela ciência da computação, define uma sequência de ações para execução de determinada equação que resulta em uma ou mais respostas. Tal processo vai se delineando com a finalidade de alcançar um objetivo de solução a uma equação e/ou proposta. Podemos entender como uma espécie de receita para chegar a determinado fim.

Assim, para chegarmos até um esboço do que seria um algoritmo do prazer, parte-se da análise das relações históricas, construídas por meio da cultura, ligadas ao sexo, corpo, rituais, dentre outros modos de erotização e demonstração do desejo.

Na sequência, apresentaremos modos de como acontecem os processos de busca das experiências com uso das tecnologias até a viabilidade de um algoritmo do prazer como via para as interações afetivas presenciais, propondo formas para um uso saudável com estratégias clínicas que nos fazem refletir sobre o papel terapêutico nesse meio.

\section{Relações históricas da sexualidade}

Se um dia o sexo esteve ligado, unicamente, ao casamento como símbolo de procriação, defendido pelo cristianismo como sua única finalidade, com as mudanças socioculturais foi se ampliando e podendo ir além. Por meio do estabelecimento da conexão sexo e amor, transcende a finalidade meramente reprodutiva e permite a sexualização do amor e erotização do sexo.

Não paramos por aí. A revolução sexual, na década de 60, com o advento da contracepção feminina, trouxe para a cena a possibilidade do sexo sem compromisso e da multiplicidade de parcerias sexuais (Wouters e Bejarano, 2006).

A ampliação das possibilidades acaba por gerar expectativas do que fazer com tantas opções. 0 manejo em como conduzir os caminhos a serem seguidos, a quais rotas direcionar e, ainda, alguns descaminhos, produzem insegurança e ansiedade. 0 equilíbrio do uso da(s) tecnologia(s) na vida das pessoas já tem se tornando fonte de inúmeros debates e suas implicações na sexualidade dos sujeitos e nos impasses vivenciados é o que se visa discutir aqui, com intuito de refletir sobre eles por meio de experiências clínicas, nascidas e alimentadas no cotidiano da atuação profissional como Psicóloga Especialista em Terapia Sexual, Diversidade Sexual e Gênero.

\section{Busca por experiências com uso de tecnologias}

A busca por experiências sexuais diversas vem sendo tema recorrente nos processos psicoterapêuticos, produzindo sentimentos antagônicos, em que empolgação e frustração contrapõem-se em muitas das situações. De acordo com Sfoggia e Kowacs (2014), as tecnologias afetam o desenvolvimento e a cultura sexual, bem como existem modos como se aprende e se manifesta a sexualidade, inclusive nas redes sociais. Esse processo não está livre de desafios e contradições, pois, de alguma maneira, produz impacto nas relações afetivo-sexuais contemporâneas.

Nesse sentido, buscou-se, por meio deste relato de experiência profissional, lançar impactos da interferência da tecnologia na (re)construção de modelos de relacionamento e suas contribuições e desserviços, no intuito de reiterar o lado bom das marcas da tecnologia na sexualidade e questionar o lado não tão belo, que pode ocasionar descontentamento, frustração e sofrimento.

0 envio de fotos íntimas, popularmente conhecido como nudes, tão comentado na atualidade, é um exemplo que pode ser encarado sob mais de uma perspectiva. A liberdade em relação aos próprios corpos traz segurança para que homens e mulheres se sintam estimulados por fotos de nudez de parceiros ou potenciais escolhas íntimas. Essa troca, para casais que estão resgatando a intimidade e investindo em ampliação de repertório nos relacionamentos, pode representar estímulo, conexão e foco no outro. Um casal, em terapia, apresentava como queixa ausência de clima, em função da rotina familiar, dinâmica dos filhos e outras questões e viu, nesse modelo de interação, uma alternativa para ampliar 0 interesse e a prática sexual e resgatar a satisfação conjugal. Aqui o nude seria uma recomendação saudável e necessária para reativação da intimidade conjugal, reforçando a continuidade do vínculo e motivação no relacionamento. Já uma adolescente, no início de sua vida sexual, ao vazar conteúdo erótico em sua primeira relação sexual, desenvolveu um estresse pós-traumático, prejudicando a continuidade de sua vida sexual, pois, nas relações seguintes, não conseguia relaxar e a penetração era dolorida e impossibilitada pelos registros de memória que indicavam exposição e risco.

Portanto, devemos estar atentos a esses dissabores, pois existe um lado negativo como 0 vazamento de intimidades. 0 caminho de libertação da própria intimidade e exploração das possibilidades diferentes de sexo que as novas conexões possibilitam é válido, desde que sob uma base segura de reciprocidade e respeito. Nesse sentido, vale se aproximar das relações sexuais virtuais, que necessitam estar protegidas pelos riscos de exposição, tomando as devidas precauções.

Cada vez mais presente nos temas abordados durante o processo terapêutico, explorar a sexualidade por meio do cibersexo auxilia no entendimento da união de práticas sexuais com o universo tecnológico. Para Lemos, Silva e Caldas (2012), as vantagens da prática do sexo virtual referem-se à facilidade no acesso, identificação anônima, mercado sem limite de possibilidades, enfrentamento do medo da rejeição, comunicação interativa, lacuna entre 
experimentar a fantasia e os reflexos nas atitudes da vida real, construção de outras identidades no âmbito virtual, bem como risco reduzido de apreensão.

Dentre os usuários da rede para sexo virtual, tem aumentando o número de adolescentes investindo nessa possibilidade, além da população adulta em geral (Lemos eVilar, 2018). Torna-se, cada vez mais instigante, demonstrado nos relatos em sessão, encontrar o que se busca de imediato, sem muito esforço de sair do próprio espaço, um conteúdo estimulantee, para al guns, providencial, em função de aliviar os medos e inseguranças relacionados à sexualidade.

Contudo, de acordo com Abreu et al. (2008), no momento em que 0 uso e 0 acesso foi sendo ampliado, as consequências negativas também se mostraram, em função do excesso, como um novo problema de saúde mental. Apontam para uma dependência em sujeitos que utilizam a internet como um modo de interação social e de comunicação, em que encontram ampliação do prazer e da satisfação, em detrimento dos acontecimentos presenciais. Estudos demonstram que 80\% dos usuários dependentes de internet e 43\% que não desenvolveram dependência, afirmam a sensação de desinibição quando conectados à rede (Greenfield, 2011).

A grande questão está pautada na transição do acesso para um modelo de dependência ou para a dinâmica de uma compulsão. Segundo Greenfiel (2011), na internet, há uma super oferta de conteúdos estimulantes às adições, nem todos exclusivos da rede, considerando que os mais aditivos, relacionados a sujeitos que precisam de acompanhamento clínico, são o conteúdo sexual e os jogos de vídeo ou computador. Por ser acessado a qualquer instante, eleva o potencial de dependência, pois "se o conteúdo é a matéria-prima, o meio de internet é a seringa psicológica que introduz o conteúdo no nosso sistema nervoso para que seja consumido" (Greenfiel 2011, p. 175).

Para Greenfiel, (2011, p.177) "esse efeito de desinibição é mais uma confirmação da internet como um meio psicoativo; o efeito alterador da consciência e do humor parece operar independente do conteúdo". No campo da sexualidade, aproximaria os sujeitos de modo menos impactante, sem busca de recursos de enfrentamento e interação. Isso afastaria o contato interpessoal e colocaria a interação virtual como centro de suas vidas? Provavelmente, sim, de maneira especial, em sujeitos com demais patologias associadas.

Os usuários afetados pelo uso excessivo, problemático para uma vida emocional saudável e equilibrada, podem estar associados a questões de vulnerabilidade individual, histórico de compulsões e transtornos de descontrole de impulsos, como padrões que justificam uma relação de excesso ou, até mesmo, dependência. "Debate-se que o usuário dependente de sexo virtual apresenta dificuldades na liberdade de escolha, comportamentos compulsivos, pensamentos obsessivos, isolamento e tempo excessivo na prática de sexo virtual" (Lemos, Silva e Caldas, 2012).

Assim, a exploração da sexualidade é um ponto que acaba impactado com 0 uso de tecnologias. Sejam novas experiências entre mulheres que sempre tiveram relações com homens, querendo viver sexualmente momentos com outras mulheres, sejam entre homens que sempre se relacionaram sexualmente com mulheres e que, com o uso da tecnologia, puderam se conectar com outros homens, tendo experiências com eles. 0 mesmo se dá com casais que, com o apoio de redes sociais, viveram experiências sexuais em trio, conseguindo encontrar esse terceiro membro pela conexão estabelecida por meio da tecnologia.

Casos em psicoterapia nesse sentido são comuns, como jovens que se abrem para experiências sexuais na tentativa de entender melhor suas próprias sexualidades por meio de redes sociais, pela facilidade de conexão com pessoas semelhantes que compreendam suas questões. Os aplicativos de encontro permitem que se determine se você gostaria de ter parceiros do outro sexo/ gênero, bem como do mesmo sexo que o seu, o que facilita a demonstração de interesse, a conversa prévia antes de um encontro, e o próprio encontro que pode ou não ter como objetivo o sexo.

Uma paciente homossexual, com dificuldade de estabelecer vínculos duradouros, vivenciou isso quando encontrou parcerias para festas e programações culturais, com pessoas heterossexuais, mas com afinidades e interesses comuns, da mesma forma em que saiu com mulheres, interessadas em relações afetivo-sexuais, mas que não tiveram a mesma continuidade que as amizades que permaneceram e proporcionaram parceria em saídas, bem como a ampliação de interação em sua agenda.

Nas inúmeras situações apresentadas nos processos terapêuticos, al guns relatos eram comuns e bem próximos quanto a expectativas e vivências. Assim, através desses meios de intersecção, foi construído o que intitulamos de algoritmo do prazer, abrindo possibilidades de entender, passo a passo, a sequência de ações que utilizam recursos digitais e tecnológicos promotores dos encontros presenciais focados na intimidade.

\section{Algoritmo do prazer}

A busca por parceria romântica tem alterado seus rumos na contemporaneidade. Não raro, pacientes relatam a busca por um par nos aplicativos de relacionamento, tais como Tinder, Happen e afins. Diante de inúmeros casos e muitas semelhanças, foi possível esboçar o que poderia ser considerado um algoritmo do prazer, dentro da perspectiva de quem busca atender ao desejo sexual, estabelecendo uma conexão que se inicia no ambiente virtual.

Se pensarmos na dinâmica da possibilidade de criação de um al goritmo do prazer no cenário atual, iniciaríamos elencando como demanda 0 atendimento do desejo sexual. Os primeiros passos sinalizados são compostos por uma série de ações práticas, tais como localizar o celular, baixar aplicativo e informar o perfil (fake ou não). Depois de repetir a busca pelo(a) parceiro(a), informar localização, definir algumas características, demonstrar interesse, uma breve conversa de identificação, sem deixar de executar algumas perguntas de segurança.

Contudo, se nada interessar, então, desistir até encontrar al guém disponível. Se o ou a parceiro(a) estiver próximo à localização, pode acontecer um encontro presencial, com ou sem jantar, bebida ou petisco e, com isso, caso o clima esquente, o sexo presencial pode acontecer.

Se não, existe a possibilidade de nudes, estimulação, sexo virtual até 0 fim da conexão. Ainda, há chances de não rolar nada, não ter internet ou algo do tipo e termos que administrar angústia, depressão, abuso de álcool e/ou demais substâncias, ou nos distrairmos com música, Netflix e, até mesmo, dormir encarando a frustração.

Nesse sentido, tolerar as frustrações é fundamental, bem como estar atento para os momentos em que o acesso à internet pode se tornar um comportamento perigoso, na medida em que se torna incontrolável e substitutivo de outros modos de relação/interação. Segundo Abreu, Góes, Vieira e Chwartzmann (2008), a expansão do número de usuários da rede provocou impactos negativos, pautados no excesso de seu uso, tornando-se uma questão a ser avaliada quanto aos danos para a saúde mental. Tais autores utilizam 
termos como "dependência de internet", "uso patológico ou problemático da internet" para descrever a inabilidade do sujeito em ter controle sobre o uso da rede e nos impactos em seu contexto social.

Muitos autores defendem que a dependência se dá pelo uso de aplicativos e não pelo acesso à internet por si só. Esses usuários acabam por utilizar a rede como um recurso social, por meio de obtenção de mais prazer e satisfação quando estão em conexão, ou seja, diante de experiências virtuais, do que nas vivencias presenciais. Torna-se muito provável que o "uso patológico da internet se trate, mais propriamente, de uma forma específica de dependência, mais condicionada a elementos da história de vida e à dinâmica da personalidade do que a qualquer alteração neurofisiológica" (Abreu, Góes, Vieira e (hwartzmann, p. 142).

Tratamos como um comportamento de dependência quando nenhuma substância psicoativa é acionada, mas, sim, como um processo psicológico, como um modo de relação com a internet em resposta a algum tipo de funcionamento e/ou estados emocionais. No caso da sexualidade, entende-se a internet como "um ciclo mais eficiente e rápido de excitação e satisfação sexual" (Greenfiel, 2011, p.181). Assim, o formato potencializado pela internet pode desencadear comportamentos sexuais compulsivos, em que o conteúdo de estímulo do componente sexual é ativado pela experiência psicoativa do ambiente virtual.

\section{Reflexo das interações afetivas na "vida real"}

Os impulsos sexuais, segundo Einstein (2013), são regulados pelos limites sociais que podem desafiar riscos de impulsividade e liberdade, bem como transcender regras de proteção, códigos morais e éticos que operam, subjetiva e socialmente, o que faz com que o questionamento acerca desses limites tênues entre uso e abuso devam ser elencados.

Por isso, de acordo com a autora supracitada, devemos estar atentos aos sinais de risco e aspectos de um uso inapropriado, em excesso ou em horários inadequados. Nesse sentido, uma boa psicoeducação, relacionada ao processo de dependência em tecnologia, é muito importante para o bom andamento do tratamento.

É importante avaliar o tempo e a frequência com que se está fazendo uso, em prol das interações sociais para minimizar o estágio de dependência. A continuidade do uso precisa ser reeditada e, de acordo com Lemos (2018), este é um ponto crucial e complexo, pois o paciente pode resistir em modificar o hábito, o que não auxilia no enfrentamento das situações ansiogênicas.

Falando em mudança de hábitos e conexão virtual, um casal, atendido em psicoterapia, busca ajuda para reconexão da vida sexual, tendo, como uma das principais queixas, o uso da pornografia, em prol de interações mútuas entre 0 par. Assistir juntos aos filmes não despertava aproximação, mas, sim, potencial erótico vivenciado individualmente, tendo como estímulo, a verbalização sobre os atos narrados a partir dos vídeos. Ao se darem conta do quanto essa prática estava distanciando-0s, foi possível trabalharmos juntos o desejo aliado à comodidade e facilidade, mas com sintomas de angústia e dependência de algo externo à relação conjugal que não permitia a conexão dos parceiros.

A busca por essa conexão existe, por exemplo, nos aplicativos de paquera, em que, em alguma medida, a expectativa de um contato presencial está colocada. Para Santos (2016), esses recursos aliam interação em tempo real, uso facilitado, mobilidade e comodidade na busca, mas ainda não estudados, no Brasil, em relação aos impactos de seu uso no comportamento afetivo e sexual das pessoas.

\section{Uso saudável das redes sociais}

Novas conexões, possibilitadas pelo uso de aplicativos, redes sociais e outros recursos tecnológicos aproximam sujeitos e ampliam 0 acesso às conexões, reais ou virtuais. Contudo, não deve estar dissociado de uma medida saudável, ou melhor, exigindo cuidados para que não seja estabelecido um padrão que vicia e aliena o indivíduo, sem deixar de considerar 0 impacto disso na interação e no coletivo. Graeml e Graeml (2004) já sinalizavam para o impacto do uso excessivo da internet no comportamento social das pessoas, apontando para subcategorias, sendo sexo e relacionamentos uma delas.

À medida em que a tecnologia pode ser uma aliada para pessoas que têm problemas de interações sociais, autoestima ou fobias sociais, isso pode gerar problemas psicológicos de isolamento, dependência de aparelhos tecnológicos ou até conectar, de forma errônea, pessoas. Casos de estupros, perseguições e catfish, que é a prática de pessoas se passarem por outras na internet com fins amorosos ou sexuais, são comuns.

Nesse sentido, buscar estratégias para não ficarmos à mercê do al goritmo são importantes e cruciais na psicoeducação de nossos pacientes. (uidado com gatilhos que levam ao uso dos aparelhos eletrônicos (celular, iPad, etc.). Diminuir o acesso aos aplicativos e redes sociais pode ocorrer, em um primeiro momento, pela exclusão ou utilização de ferramentas que reduzam esse acesso. Em algumas situações, torna-se importante, inclusive, desativar notificações e deixar o celular no silencioso ou modo noturno, para que possa se estabelecer concentração e conexão com outros elementos.

A busca por outras formas de contato também auxilia a percepção de capacidade dos sujeitos para além do universo digital e/ou virtual. É importante entender que a tecnologia e o contato virtual podem ser usados como um recurso de experimentação e o start para um processo de aproximação, mas não como finalidade absoluta para aproximar, unicamente, os sujeitos.

Nesse sentido, cabe o cuidado de aproximar quem está longe, sem afastar pessoas próximas e disponíveis que estejam perto. Além disso, devem ser estabelecidos os limites de intimidade e privacidade. 0 anonimato aumenta a liberdade em relação à exposição e pode gerar riscos, como o vício em depender, única e exclusivamente, da tecnologia para se relacionar. Dessa forma, instiga a desinibição, anonimato e possibilidade de criar, fantasiar e viver outras possibilidades. Conforme Greenfiel (2011, p.178), "a fantasia e o desempenho de papéis via internet são muito atraentes e se notam, principalmente, nos jogos, bate-papo sexual (cibering) e em situação de redes sociais".

Para uma paciente com diagnóstico de ansiedade social e marcas de relacionamentos abusivos, o contato virtual possibilitou conhecer e se aproximar de pessoas por meio das redes sociais, até conversas mais íntimas. Nesse caso, cabe salientar, conforme relatam Abreu et al (2008), a internet como um meio de estabelecimento de vínculos que, por serem virtuais, minimizem a ansiedade. Greenfiel (2011) aborda os benefícios secundários, ou seja, indiretos, que reforçam o padrão de dependência, os quais se apresentam como meio de evitação a situações ansiogênicas, tais como a interação social, o desempenho escolar ou profissional, fugindo da proximidade de vínculos familiares, de amizade ou sociais. 
A internet limita e simplifica as deixas de inteligência socioemocional necessárias para um nível de interação mais manejável. Para a maioria dos usuários, ela diminui e atenua os níveis de atenção, interação, risco emocional e conexão íntima necessários no relacionamento social. Ela reduz o se relacionar a um nível tolerável. Para pessoas com dificuldade de aprendizagem, déficit de atenção, transtornos desenvolvimentais globais, ansiedade social e fobias, a internet passa a ser um ambiente seguro, previsível, circunscrito (Greenfiel, 2011, p. 182).

Nesse caso de ansiedade social, a troca de ideias, conexão do desejo e novas práticas puderam ser exploradas, bem como sensações táteis e conhecimento de suas zonas erógenas antes não desvendadas, como uma possibilidade de se conectar consigo para viabilizar o acesso ao outro. Esse recurso de utilizar a tecnologia como um meio despertou credibilidade e ampliação de suas habilidades sociais, treinadas em sessão, para o encorajamento de enfrentar os contatos presenciais, acessando a finalidade de engajar-se em relações presenciais.

Em nenhum momento foi deixado de ser sinalizado que o contato virtual pudesse substituir o presencial, bem como a auto erotização e masturbação estivessem a serviço de evitar a interação, mas sim, explorar o autoconhecimento e a autoconfiança, visto que sujeitos com ansiedade social apresentam, segundo Caballo (2016), déficit nas habilidades sociais e se beneficiariam na experimentação, no aprendizado e na ampliação de tais habilidades como meio de conexão dos sujeitos com seus ambientes. Contudo, implica em exposição a situações temidas, contrariando o recurso básico de evitação das situações que desencadeiam ansiedade para que, em algum momento, seja possível não somente reduzir o sintoma da ansiedade, como atuar na reestruturação cognitiva e na experiência e comportamentos saudáveis.

Nesse sentido, a expressividade virtual forneceu confiança e sensação de adequação às situações vivenciadas no cotidiano, ancorada por uma espécie de autorização para experimentar situações antes evitadas, fazendo com que 0 uso da tecnologia representasse um elo entre a paciente e os possíveis parceiros românticos.

\section{Estratégias clínicas}

$\mathrm{Na}$ atualidade, desconsiderar o recurso tecnológico e as possibilidades lançadas pelo "algoritmo do prazer" representaria um prejuízo nas relações terapêuticas. A construção de intervenções, baseadas em tentativas e, até mesmo, equívocos, vai reeditando modos de subjetivação e ampliação de recursos aos sujeitos. Muitas vezes, demonstrar curiosidade e se aproximar das realidades virtuais, vivenciadas pelos sujeitos, pode proporcionar pistas potentes para a evolução terapêutica.

0 potencial em identificar o modo como o sujeito interpreta as situações e vivencia suas emoções faz com que possamos conhecer seus pensamentos automáticos, o sentimento e quais poderiam ser os gatilhos para o sofrimento. Nem sempre conseguimos acessar as crenças, embora possamos esboçar hipóteses sobre o que desencadeia o sofrimento.
0 relato acerca das experiências no ambiente virtual e nos modos de conexão da atualidade fala muito do funcionamento, estilo e personalidade do nosso paciente, a maneira como estabelece seus vínculos e se apropria da condução de sua vida para construir a própria história, amparada pelo acolhimento no setting terapêutico.

0 importante, no entendimento clínico, segundo Abreu et al. (2008), seria promover a reestruturação cognitiva relacionada ao modo de aplicabilidade do uso das redes, bem como observar o tempo de uso, os gatilhos que levam ao consumo de internet, os modos de interação e o treinamento de habilidades sociais que permitam aos sujeitos contatos com assertividade fora do ambiente virtual. Interromper o uso não seria uma medida possível nos dias de hoje, nem deve ser um objetivo do tratamento, mas sim, a busca por um uso com menor disfuncionalidade e plena liberdade de escolha, com alternância dos hábitos e estratégias para adequação de sua relação com a internet.

\section{Considerações finais}

A medida do uso e a percepção do abuso nas relações atravessadas pelo advento da tecnologia marcam a contemporaneidade de modo peculiar, pois, atualmente, não existe a possibilidade de alienação dos recursos tecnológicos. Contudo, o excesso pode acarretar prejuízos e desconectar os sujeitos das vivências presenciais que consolidam as relações e aproximam os sujeitos no cotidiano.

Entretanto, nem todos/as usuários/as tornar-se-ão dependentes, muitas pessoas terão, inclusive, benefícios. O benefício é conseguir usufruir como meio e não somente enquanto um fim que se encerra nele mesmo. A proposta de um algoritmo do prazer seria pautada, justamente, nesse potencial de apoio, incentivo e motivação, no uso com moderação, na medida entre assertividade e conexão. A tecnologia como recurso de aproximação, não como sinônimo de distanciamento presencial.

Precisamos, bem mais do que acolher, entender e ressignificar o uso da tecnologia, discutindo os impactos. Para que possamos nos aproximar, no intuito de estabelecer uma relação com essa complexidade, é essencial não julgar e acreditar que podemos utilizar, como recurso terapêutico, alternativas possíveis, sem, contudo, ampliá-las em grande escala para não dificultar ações concretas que possam manter uma média saudável de aproximação e, também, de distanciamentos, quando necessários.

Assim, a busca por um modo de representação dessas vivências permite-nos repensar as intervenções terapêuticas e colocam a prática clínica em uma dimensão que exige não somente ampliar os significados, mas, também, estarmos atentas ao contexto, aos signos apresentados, aos ditos e não ditos que 0 ambiente virtual é capaz de proporcionar.

\section{Referências}

Abreu C.N., Góes D.S., Vieira A., Chwartzmann F. (2008). Dependência de Internet. In. Abreu CN, Tavares H, Cordas T. Manual Clínico dos Transtornos do Controle dos Impulsos. Porto Alegre: Artmed.

Caballo, V.E (2016). Manual de Avaliação das Habilidades Sociais. São Paulo: Santos.

Eisenstein, E. (2013). Desenvolvimento da sexualidade da geração digital. Adolescência e Saúde. Rio de Janeiro, v. 10, p. 61-67. 
Graeml, K.S.; Volpi, J.H.; Graeml, A.R. (2004). 0 impacto do uso (excessivo) da Internet no comportamento social das pessoas. Revista Psicologia Corporal. Vol.5.

Greenfield, D. (2011) As propriedades de dependência do uso de internet. In Young, K.S; Abreu, C.N. (Org) Dependência de Internet: manual e guia de avaliação e tratamento. Porto Alegre, Artmed.

Lemos, I.L., Silva, M.C.M.D.M, I.L., Caldas, M.T. (2012). Dependência de Sexo Virtual (cibersexo): uma revisão da literatura. Neurobiologia, 75(3-4), pgs. 135-144.

Lemos, I.L., Vilar, J.I. (2018) Black Mirror e as dependências tecnológicas: as múltiplas telas hipnóticas. In Cardoso, B.L.A \& Barletta, J.B. Terapias Cognitivo-comportamentais: Analisando teoriae prática por meio deffimes. Novo Hamburgo: Sinopsys.

Santos, S.C. (2016) Meu tinder tábombando!. Geolocalização, sociabilização e vivência da sexualidade. Reunião Brasileira de Antropologia: João Pessoa.

Sfoggia, A.; Kowacs, C. (2014). Sexualidade e novas tecnologias. Revista Brasileira de Psicoterapia, v.16, no2.

Wouters, C.; Bejarano, V.C. (Tradução e adaptação). (2006) Tecnologia e 0 Equilibrio da Sensualidade no Amor e no Sexo. Revista Gestão Industrial V.02, n.03: p. 174-183. 